\title{
Stress and Deformation Analysis of Joint Plate Depending on Truss Joint Design of Carrying Structure
}

\author{
Elizabeta Hristovska, Sevde Stavreva \\ Faculty of Technical Sciences-Bitola, Makedonska falanga 37, Bitola, R. N. Macedonia
}

\begin{abstract}
This article presents the stress and deformation shape of joint plate in two commonly used constructive designs of truss joints of a rotating excavator's load-carrying structure. A local analysis of stresses and deformations of the joint plate have been conducted taking into consideration the most loaded truss joint of the working wheel's load-carrying structure on specific rotating excavator, having a riveted design, as well as the theoretically determined forces affecting the joining trusses of the truss joint. These activities are performed employing FEM (Finite Element Method) modelling of the truss joint and using a software package for this purpose, in view of defined characteristic static and dynamic loads. Nowadays, the load-carrying structures are more often made by welding, so it is in our interest as it would affect the stress and deformation shape of the subject truss joint in welded design, bearing the same load conditions.
\end{abstract}

Keywords - carrying structure, FEA modeling, riveted truss joint, welded truss joint, stress analysis.

DOI: 10.18421/TEM102-51

https://doi.org/10.18421/TEM102-51

Corresponding author: Elizabeta Hristovska, University St. Kliment Ohridski - Bitola, Faculty of Technical Sciences - Bitola, Makedonska falanga 37, Bitola, R. N. Macedonia.

Email: elizabeta.hristovska@uklo.edu.mk

Received: 10 March 2021.

Revised: 22 April 2021.

Accepted: 30 April 2021.

Published: 27 May 2021.

(cc) BY-NC-ND (C) 2021 Elizabeta Hristovska \& Sevde Stavreva; published by UIKTEN. This work is licensed under the Creative Commons AttributionNonCommercial-NoDerivs 4.0 License.

The article is published with Open Access at www.temjournal.com

\section{Introduction}

The load-carrying structure of the working wheel on a rotating excavator is spatial lattice girder with complex design [1]. The truss joints of this structure connect the constructive elements (trusses), and its cross-sections are a combination of two or more standard profiles having different form features, inherent to these constructions. The fixing of the trusses onto the truss joint steel plate is done by riveting, and more often by welding lately.

Given the regime of work of the excavator, the carrying structure as a whole, as well as its structural elements, are exposed to dynamic loads, often unpredictable bringing about complex states of stress appear.

The insight into the stress-deformed shape, especially at the most loaded truss joint of the carrying structure of the working wheel (being the most loaded structure of the excavator), has a special importance as to the regular operation and long exploitation lifetime of the excavator elements, as well as for the excavator in general. Hence, it is necessary to establish a methodology for modeling of this truss joint [2].

This article establishes the methodology for modeling of a truss joint of rotating excavator's loadcarrying structure, applied to the most loaded truss joint of the working wheel's carrying structure of the rotating excavator SRs-630, produced by the German company TAKRAF, working under the exploitation conditions in the coal mine "Suvodol" in Bitola, Macedonia (shown in Figure 1).

The most loaded truss joint of this carrying structure is determined based on conducted global static analysis, whereby the loads are also set up for the joining trusses of the subject truss joint under static and dynamic loads [3]. 


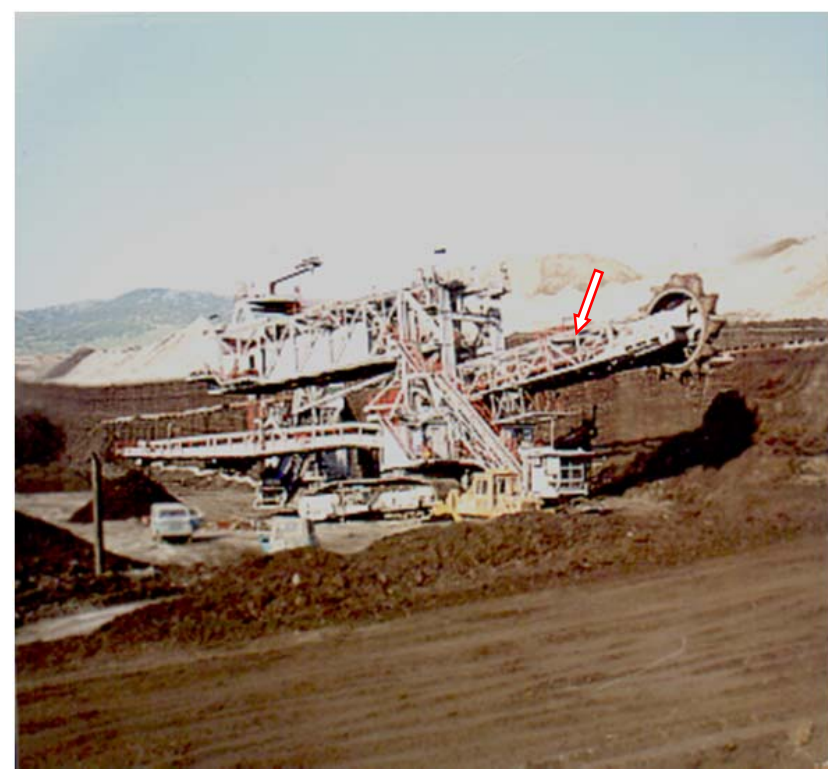

Figure 1. View of the rotating excavator SRs-630, the working wheel carrying structure being marked with red arrow

The theoretical research of the loads bearing on the joining trusses of this truss joint is done by structural analysis of the load-carrying structure using postulates of statics, modelling and computer analyses [4], made available by the software package SAP 2000. This procedure allows deriving the values of the magnitudes relative to the tension or the pressure forces at the joining trusses, on the spot of their neutral axis, in respect to the specific static and dynamic loads.

The load-carrying structure (Figure 1) of the working wheel on this excavator is spatial lattice girder having $18.55 \mathrm{~m}$ in length and a rectangular cross-section with following dimensions: width 3.5 $\mathrm{m}$ and height $2.4 \mathrm{~m}$.

The load-carrying structure is made of a combination of materials (steels).

This load-carrying structure of the working wheel comprises two chief cantilevers, the chief cantilever I (front side of the lattice) and the chief cantilever II (back side of the lattice), an upper and an under connection (upper side and under side of the lattice) and two transverse frames (transverse frame 1 and transverse frame 7). The mentioned parts are shown in Figure 2.

The load-carrying structure is suspended by clamp dogs within the panel 1 , at the end truss joints of the upper connection.

The clamp dogs are also made from steel, with a rectangular cross-section and have the following dimensions $0.4 \mathrm{~m} \mathrm{x} 0.03 \mathrm{~m} \mathrm{[1]}$.

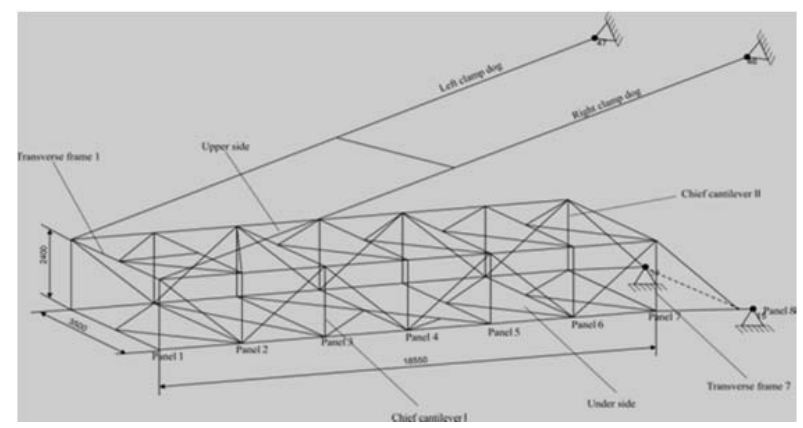

Figure 2. Numerical model of the working wheel's carrying structure with its constituent components

The numerical model of the clamp dogs and the load-carrying structure of the working wheel with its constituent components are shown in Figure 2.

\section{Modelling of the most Loaded Truss Joint in Both Constructive Designs}

\section{Modelling of the Geometry of the most Loaded Truss Joint}

Considering the global static analyses of the working wheel's carrying structure on the rotating excavator SRs-630 used in the coal mine "Suvodol" in Bitola, the most loaded truss joint of this structure is the joint numbered as 24 (Figure 3).

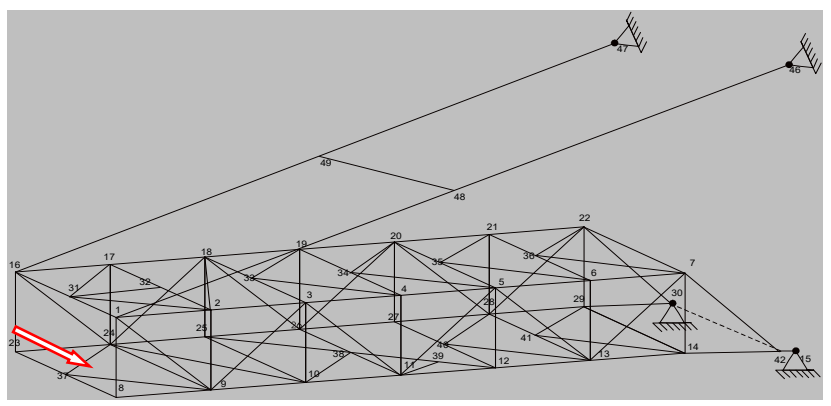

Figure 3. Geometric model of the working wheel's carrying structure displaying the layout of all the truss joint $s$ and the most loaded truss joint marked by red arrow

The geometric model of the most loaded truss joint [5] of the lattice girder together with a layout of the joining trusses is shown in Figure 4, while the geometry of the real model of this joint is shown in Figure 5.

These figures visualize the constructive design of this truss joint, which is very complex for several reasons: the constructive design of the truss joint being a three-dimensional one, the truss joint connecting eight trusses, each of the trusses having a complex transversal section, worked out by connecting profiled carriers, while the mounting of the eight trusses onto the joint steel plate is done by rivets within the current design of the truss joint and welds in the proposed design [6]. 


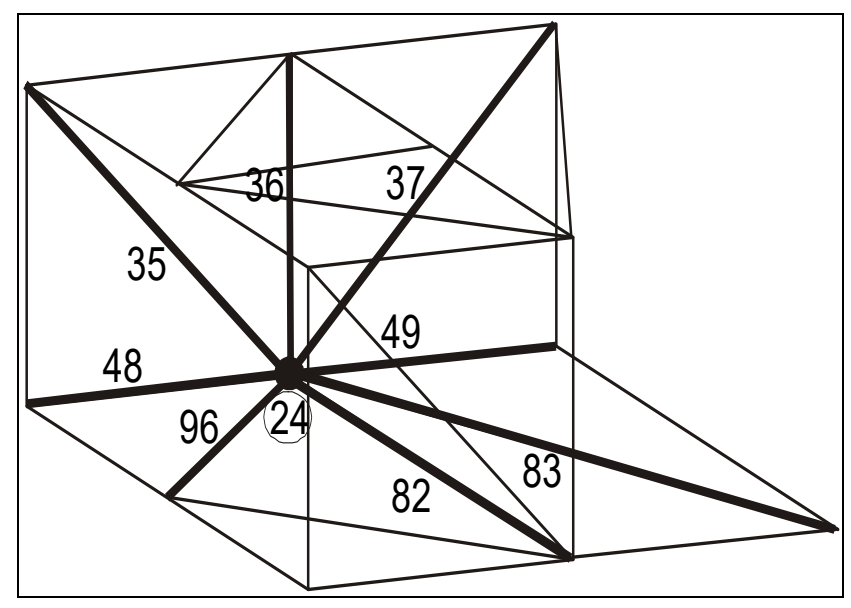

Figure 4. Geometric model of the most loaded truss-joint of the carrying structure with an outlay of the joining trusses

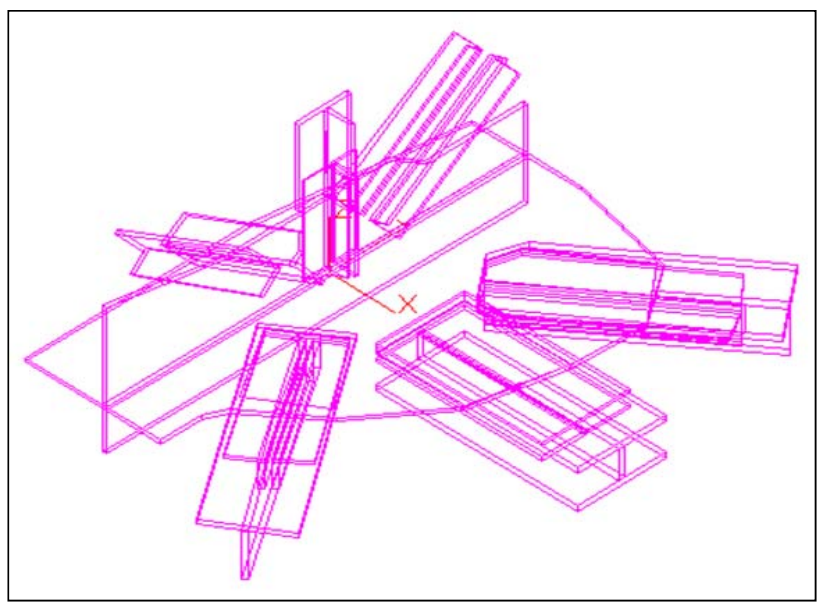

Figure 5. Geometry of the real model of the most loaded truss

\section{FEA Modelling of the Joint Plate of the most Loaded Truss Joint}

\section{Modelling of the Geometry}

The FEM modelling [7], [8] of the joint plate of the most loaded truss joint is made using the computer program package ALGOR-FEA. The process of modelling is taking into consideration all the characteristics of the geometry of the truss joint: exact geometrical measurements of the joint steel plate, identical disposition of the trusses in the same way as in the real model of the joint (Figure 5), same configuration of the transversal sections of the trusses, exact location of the rivets and welds seams on the joint steel plate by size and location, shown in Figure 6 a) and Figure 7.

All these characteristics are taken into consideration with a regard to the model of truss joint 24 having usable shape for computer analysis of its stress-deformed condition [9], [10], using the mentioned program package.

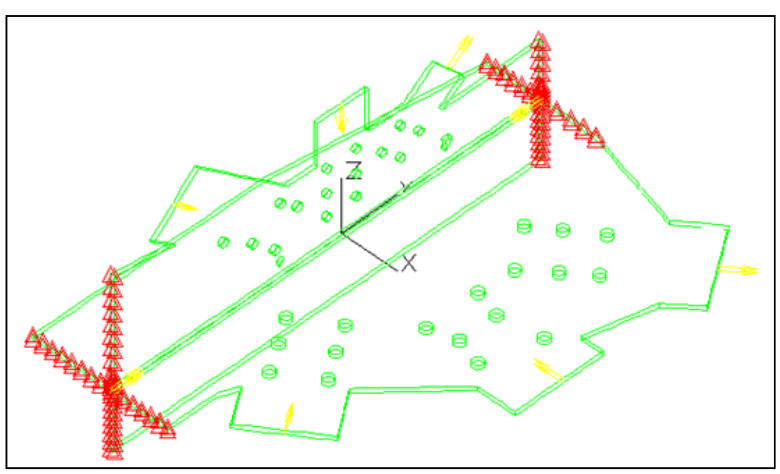

a)

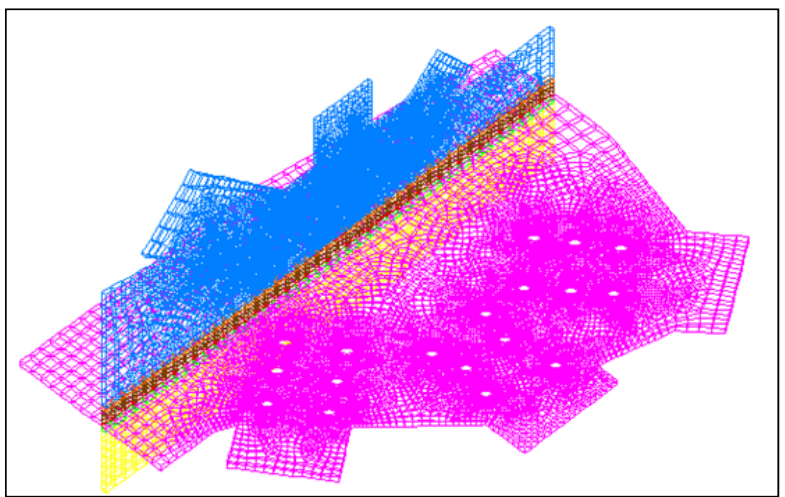

b)

Figure 6. FEA model of the joint plate of the most loaded truss joint done in riveted design by a) an outlay of the holes for the rivets and $b$ ) a created mesh of $3 D$ finite elements

The FEA model (mesh model) of the joint plate of the most loaded truss joint 24 having riveted design, employing a created mesh of finite elements is shown in Figure $6 \mathrm{~b}$ ). The creation of finite elements, being among the most difficult problems in modelling, is made via combination of manual and automatic creation, bearing in view the complex geometry of the truss joint and its $3 \mathrm{D}$ configuration, the same is being limited by the program package for this purpose. The model employs 3D finite elements with triangular and quadrangular transversal section.

The final model has following features: a total of 79924 lines, whereof 79753 processed lines, 15624 3D finite elements, whereby $96.2 \%$ engaging the program memory, indicating the complexity of this model.

The FEA model of the joint plate of the most loaded truss joint 24 sporting welded design and having a generated mesh of finite elements is shown in Figure 7.

Generating of the finite elements is also made combining manual and automatic generating, in view of the complex geometry of the joint presented in a spatial configuration and having the same limitations of the program package used. Spatial finite elements are used with triangular and quadrangular transversal section. 
The final model has following characteristics: a total of 19340 lines from which 19168 lines are processed, 3496 spatial finite elements, by using $22.12 \%$ of the program memory, which indicates a simplified model compared to the model of riveted truss joint.

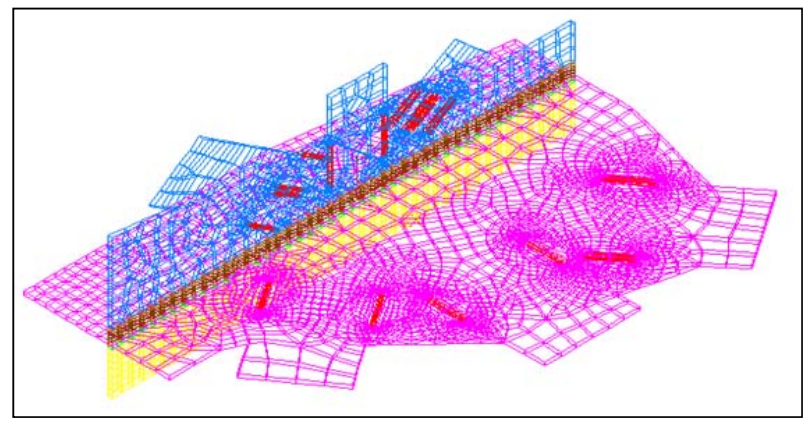

Figure 7. FEA model of the joint plate of the most loaded truss joint done in welded design, with generated mesh

\section{Modelling of the Loads and Boundary Conditions}

Entered data during the examination of stressdeformed shape of the joint plate at the most loaded truss joint are theoretically calculated loadings (forces of tension or pressure) impacting the joining trusses of the joint under the characteristic working regimes [11] and under maximal resistance of digging (by global static analyses).

The forces are defined in subprogram SuperDraw II by direction, sense, point of action and magnitude. The direction of the forces runs along the geometrical axis of the trusses, and the sense is being the sense of tension force or pressure. The points of action of the forces are at the joint of the FEA model located nearest to the geometrical axis of the trusses (where the intersection of the trusses has largest dimensions) on the both sides of the joint plate, because the intersections of the trusses are designed by placing elements of the both sides of the joint steel plate. The intensities of the forces are given as numerical data.

The methodology of applying the loads to the FEA model of the joint plate is shown in Figure 8 for the most loaded truss joint sporting riveted design and in the Figure 9 featuring a welded design. The mentioned figures emphasize the forces given by yellow arrows.

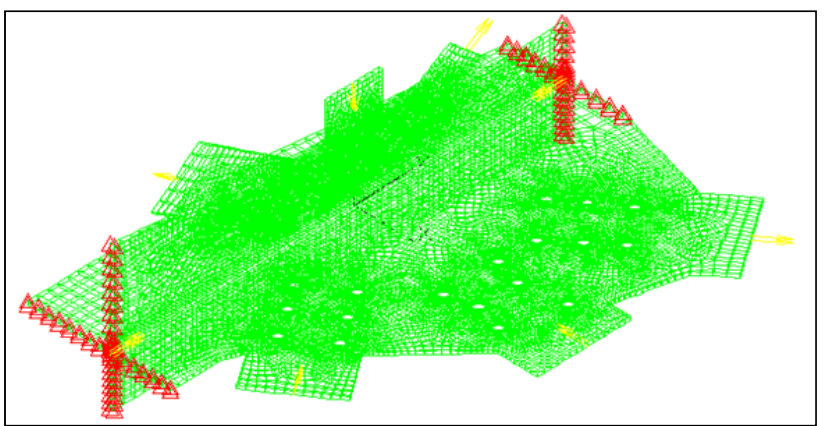

Figure 8. FEA model of the joint plate of the most loaded riveted truss joint, with loading forces and supporting points

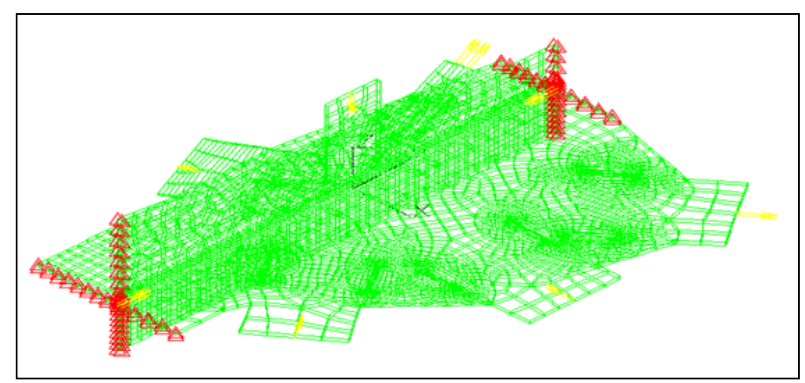

Figure 9. FEA model of the joint plate of the most loaded welded truss joint, with loading forces and supporting points

The boundary conditions for the structural analysis of the joint plate of the most loaded truss joint are defined at the points of joining of the truss joint onto the load-carrying structure, shown in Figures 8 and 9 (with red triangles).

Figure 8 shows the boundary conditions for the most loaded riveted truss joint and Figure 9 for the most loaded welded truss joint.

These FEA models is being used for analysis of stress-deformed shape [12] of the truss-joint exposed to specific static and dynamic loads under characteristic working regimes of the excavator, and within the conditions prevailing in the coal mine "Suvodol" - Bitola.

\section{Stress-Deformed Shape of the Joint Plate of the most Loaded Truss Joint}

\section{Stress-Deformed Shape Under Static Loads}

Stress-deformed shape of the joint plate of the most loaded truss joint under static loads is obtained for the three characteristic positions on the loadcarrying structure:

- Uppermost position;

- Horizontal position;

- Nethermost position.

For example, the Figures 10, 11 and 12, show the stress-deformed shape of the joint plate of the most loaded riveted truss joint, under static loads in horizontal position of the load-carrying structure, being the state of maximum static loads.

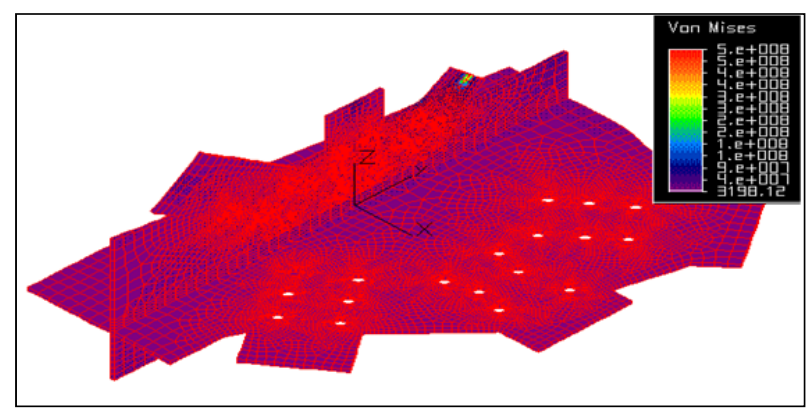

Figure 10. Magnitudes of stresses for the joint plate of the most loaded riveted truss joint, under static loads 


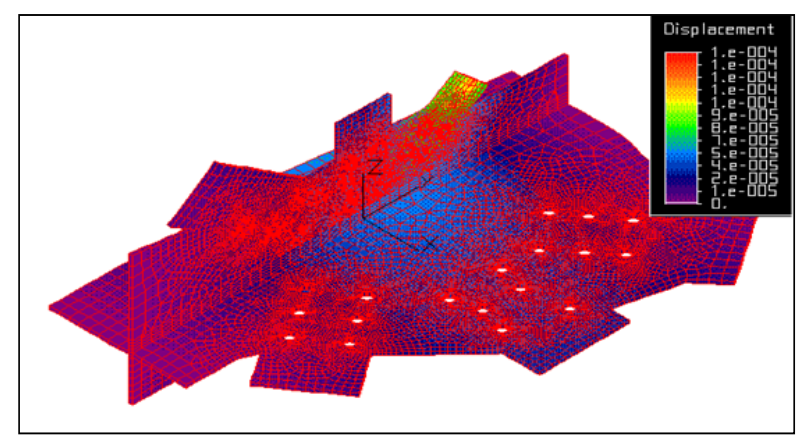

Figure 11. Magnitudes of displacements for the joint plate of the most loaded riveted truss joint, under static loads

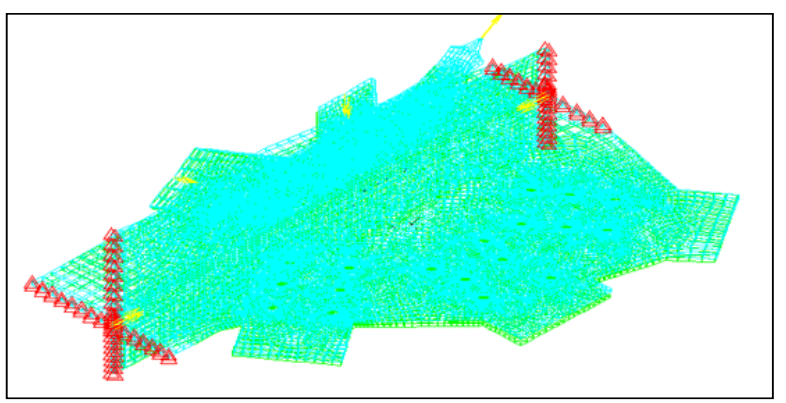

Figure 12. Deformed shape for the joint plate of the most loaded riveted truss joint, under static loads

The magnitudes of the stresses are given in $\mathrm{N} / \mathrm{m}^{2}$, and the displacement in $\mathrm{m}$.

The Figures 13, 14 and 15 show the stressdeformed shape on the joint plate of the most loaded welded truss joint, under static loads in horizontal position of the load-carrying structure.

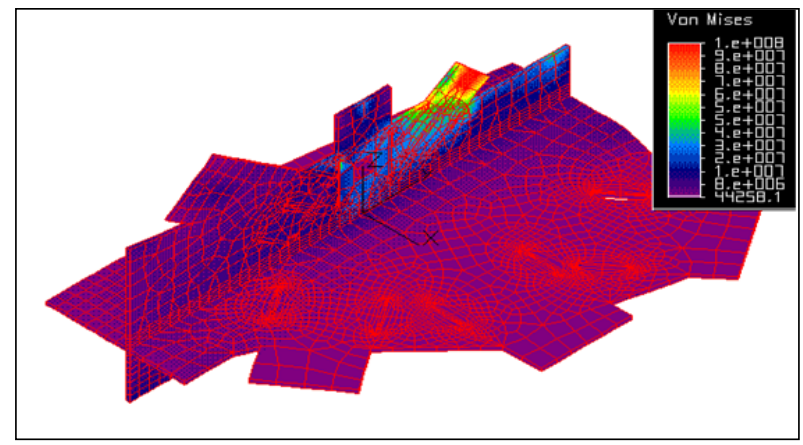

Figures 13. Magnitudes of stresses for the joint plate of the most loaded welded truss joint, under static loads

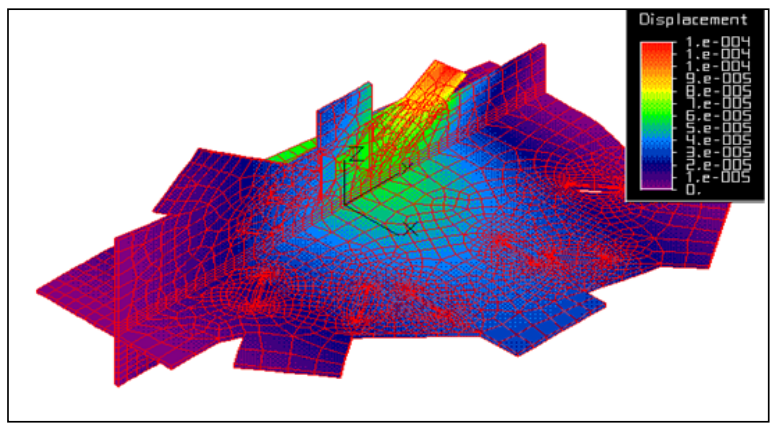

Figures 14. Magnitudes of displacements for the joint plate of the most loaded welded truss joint, under static loads

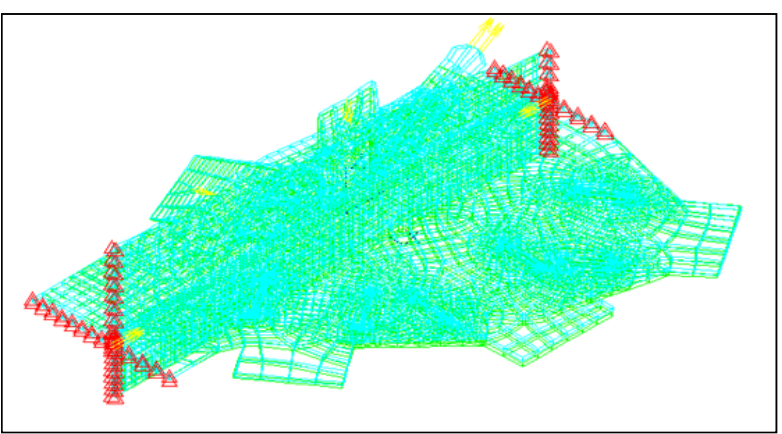

Figure 15. Deformed shape for the joint plate of the most loaded welded truss joint, under static loads

The magnitudes of the stresses are also given in $\mathrm{N} / \mathrm{m}^{2}$, and the displacement in $\mathrm{m}$.

The FEA model of the joint plate of the most loaded horizontal position of the load-carrying structure is being the state of maximum static loads.

\section{Stress-Deformed Shape Under Dynamic Loads}

Stress-deformed shape of the joint plate of the most loaded truss joint under dynamic loads is obtained under the characteristic working regimes:

- First regime - Uppermost position (of the loadcarrying structure) and turning left;

- Second regime - Uppermost position (of the load - carrying structure) and turning right;

- Third regime - Horizontal position (of the loadcarrying structure) and turning left;

- Fourth regime - Horizontal position (of the loadcarrying structure) and turning right;

- Fifth regime - Nethermost position (of the loadcarrying structure) and turning left;

- Sixth regime - Nethermost position (of the loadcarrying structure) and turning right.

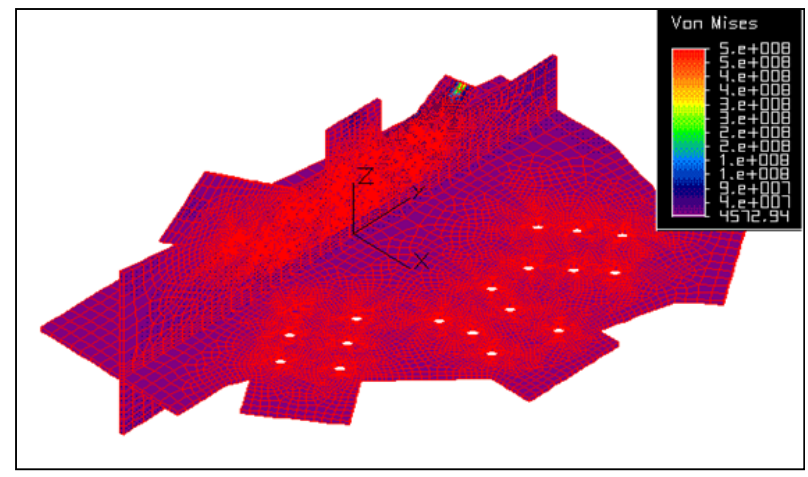

Figure 16. Magnitudes of stresses for the joint plate of the most loaded riveted truss joint, under dynamic loads

For example, the Figures 16, 17 and 18 show the stress-deformed shape of the joint plate of the most loaded riveted truss joint, under dynamic loads in the most unfavorable regime of loading. The most unfavorable regime of loading is the Third regime, mentioned above. 
The magnitudes of the stresses are given in $\mathrm{N} / \mathrm{m}^{2}$, and the displacement in $\mathrm{m}$.

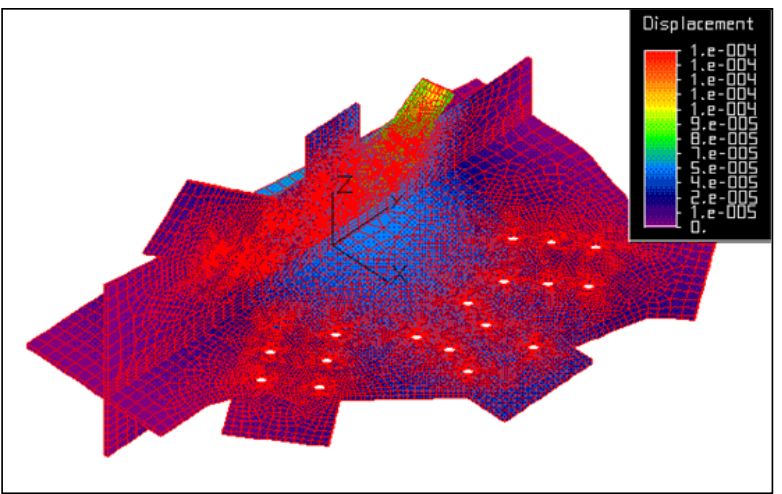

Figures 17. Magnitudes of displacements for the joint plate of the most loaded riveted truss joint, under dynamic loads

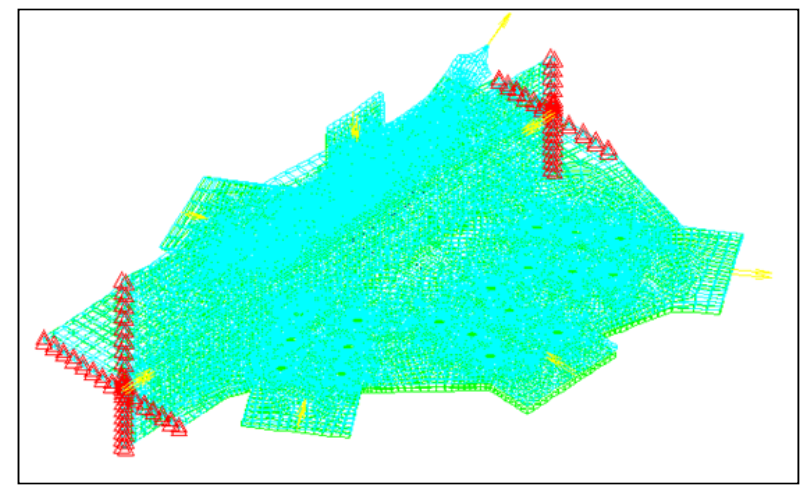

Figure 18. Deformed shape for the joint plate of the most loaded riveted truss joint, under dynamic loads.

The Figures 19, 20 and 21 show the stressdeformed shape of the joint plate of the most loaded welded truss joint under dynamic loads in the mentioned most unfavorable regime of loading.

The magnitudes of the stresses are also given in $\mathrm{N} / \mathrm{m}^{2}$, and the displacement in $\mathrm{m}$.

The material used for manufacturing the joint plate is steel [1] having well-established properties: modulus of elasticity $E$, shear modulus $G$, Poisons coefficient , linear expansion coefficient and density $\rho$, entered as starting data in FE analysis.

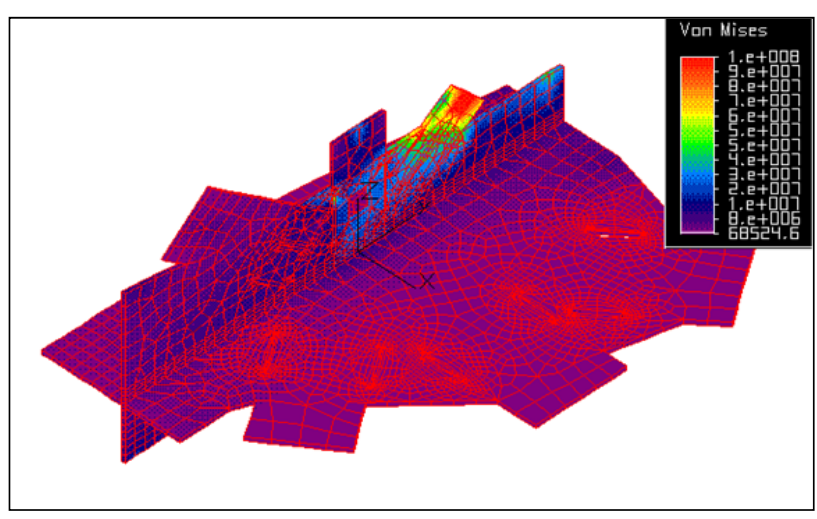

Figure 19. Magnitudes of stresses for the joint plate of the most loaded welded truss joint, under dynamic loads

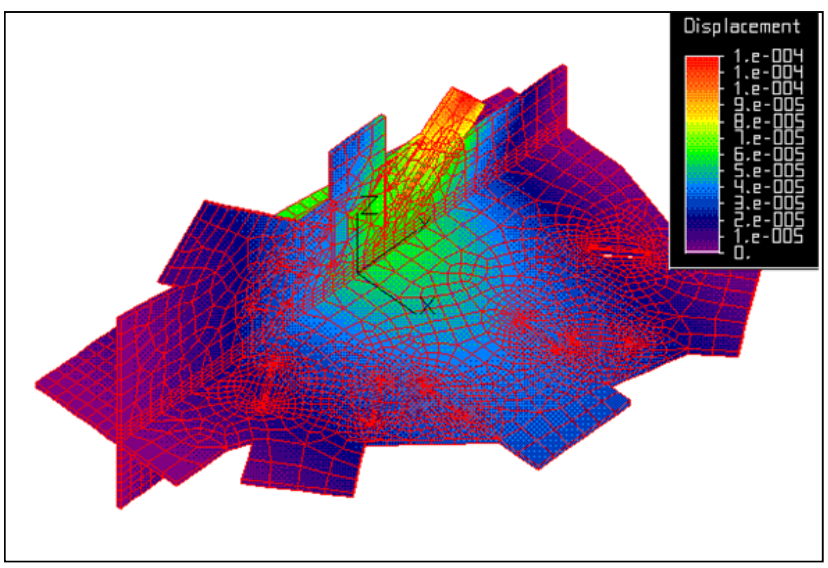

Figure 20. Magnitudes of displacements for the joint plate of the most loaded welded truss joint, under dynamic loads

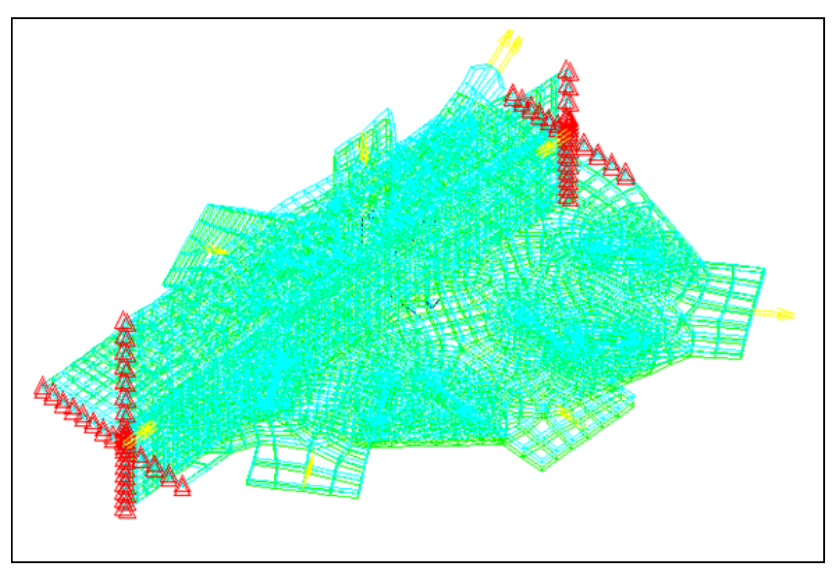

Figure 21. Deformed shape for the joint plate of the most loaded welded truss joint, under dynamic loads

The analysis of the stress magnitudes and distribution [13] on the surface of the joint plate indicates that under static and dynamic loads under the six working regimes of the excavator the maximum stresses are located on the joint plate around the axis of symmetry of the truss 37 (Figure 4 ), i.e. in the junction of the truss with the joint plate, more precisely in mesh joint in which the force is set up for this truss.

The distribution of other magnitudes of stresses on the surface of the joint plate for all load regimes is illustrated in figures mentioned above.

\section{Extreme Magnitudes of Stresses and Displacements on the Joint Plate}

\section{For Riveted Design of the Truss Joint}

The extreme magnitudes of stresses and displacements in the most loaded truss joint are derived from the analysis of the results of its stressdeformed shape and they are shown in Tables 1 and 2. 
Table 1. Extreme magnitudes of stresses and displacements for the truss joint in riveted design under static loads

\begin{tabular}{|c|c|c|}
\hline \multirow{2}{*}{$\begin{array}{c}\text { Positions of load- } \\
\text { carrying structure }\end{array}$} & \multicolumn{2}{|c|}{$\begin{array}{c}\text { Truss joint 24 } \\
\text { (the most loaded truss joint) }\end{array}$} \\
\cline { 2 - 3 } & $\begin{array}{c}\text { Stress } \\
\text { in } \mathrm{kN} / \mathrm{cm}^{2}\end{array}$ & $\begin{array}{c}\text { Displacement } \\
\text { in cm }\end{array}$ \\
\hline Uppermost & $0.00044-10$ & $0-0.0131$ \\
\hline Horizontal & $0.00032-12$ & $0-0.0169$ \\
\hline Nethermost & $0.00048-11$ & $0-0.0149$ \\
\hline
\end{tabular}

Table 2. Extreme magnitudes of stresses and displacements for the truss joint in riveted design under dynamic loads

\begin{tabular}{|l|c|c|}
\hline \multirow{2}{*}{\begin{tabular}{c}
\multirow{2}{*}{$\begin{array}{c}\text { Working } \\
\text { regimes of } \\
\text { excavator }\end{array}$} \\
\cline { 2 - 3 }
\end{tabular}} & $\begin{array}{c}|c| \\
\text { Truss joint 24 } \\
\text { (the most loaded truss joint) }\end{array}$ \\
\hline First & $\begin{array}{c}\text { Stress } \mathrm{kN} / \mathrm{cm}^{2} \\
\text { in }\end{array}$ & $\begin{array}{c}\text { Displacement } \\
\text { in cm }\end{array}$ \\
\hline Second & $0.00038-10$ & $0-0.0123$ \\
\hline Third & $0.00039-10$ & $0-0.0121$ \\
\hline Fourth & $0.00046-12$ & $0-0.0168$ \\
\hline Fifth & $0.00057-12$ & $0-0.0168$ \\
\hline Sixth & $0.00025-11$ & $0-0.0143$ \\
\hline
\end{tabular}

Table 1 displays minimum and maximum magnitudes of stresses and displacements under static loads for the characteristic positions of the working wheel's load-carrying structure of the excavator SRs630 , and the Table 2 gives those magnitudes under dynamic loads under all six working regimes of the excavator.

\section{For Welded Design of the Truss Joint}

The extreme magnitudes of stresses and displacements in the most loaded truss joint in proposed welded design [14], are derived from the analysis of the results of its stress-deformed shape and they are shown in Tables 3 and 4.

Table 3. Extreme magnitudes of stresses and displacements for the truss joint in welded design under static loads

\begin{tabular}{|c|c|c|}
\hline \multirow{2}{*}{$\begin{array}{l}\text { Positions of } \\
\text { load-carrying } \\
\text { structure }\end{array}$} & \multicolumn{2}{|c|}{$\begin{array}{c}\text { Truss joint } 24 \\
\text { (the most loaded truss joint) }\end{array}$} \\
\hline & $\begin{array}{c}\text { Stress } \\
\text { in } \mathrm{kN} / \mathrm{cm}^{2}\end{array}$ & $\begin{array}{l}\text { Displacement } \\
\text { in } \mathrm{cm}\end{array}$ \\
\hline Uppermost & $0.0027-6$ & $0-0.0096$ \\
\hline Horizontal & $0.0044-8$ & $0-0.0123$ \\
\hline Nethermost & $0.0037-7$ & $0-0.0109$ \\
\hline
\end{tabular}

Table 4. Extreme magnitudes of stresses and displacements for the truss joint in welded design under dynamic loads

\begin{tabular}{|c|c|c|}
\hline \multirow{2}{*}{$\begin{array}{c}\text { Working } \\
\text { regimes of } \\
\text { excavator }\end{array}$} & \multicolumn{2}{|c|}{$\begin{array}{c}\text { Truss joint 24 } \\
\text { (the most loaded truss joint) }\end{array}$} \\
\cline { 2 - 3 } & $\begin{array}{c}\text { Stress } \\
\text { in } \mathrm{kN} / \mathrm{cm}^{2}\end{array}$ & $\begin{array}{c}\text { Displacement } \\
\text { in cm }\end{array}$ \\
\hline First & $0.0054-5$ & $0-0.0091$ \\
\hline Second & $0.0033-5$ & $0-0.0090$ \\
\hline Third & $0.0069-8$ & $0-0.0123$ \\
\hline Fourth & $0.0035-8$ & $0-0.0123$ \\
\hline Fifth & $0.0060-7$ & $0-0.0105$ \\
\hline Sixth & $0.0033-6$ & $0-0.0105$ \\
\hline
\end{tabular}

The Table 3 gives the minimum and maximum magnitudes of stresses and displacements under static loads for the characteristic positions of the working wheel's load-carrying structure of the excavator SRs630 , and the Table 4 displays those magnitudes under dynamic loads under all six working regimes of the excavator.

\section{Conclusion}

General conclusions drawn from the performed exploration and other activities in this article are the following:

- Researching the local stress-deformed shape of the joint plate of the most loaded truss joint in the specific rotating excavator's working wheel load-carrying structure, this article defines an original model for examination of the stresses and deformations of the joint plate of a truss joint at the load-carrying structures of rotating excavators.

- The article establishes an exploration methodology of stress-deformed shape which can be used for the riveted and welded truss joints of excavator's 3D lattice girder and can also be generalized regarding to other riveted and welded carrying structures.

- This methodology, based on usage FEM modelling and FE analysis of the joint plate, gives a clear picture of stress deformed shape of the riveted and welded truss joints with allocation of the stresses and displacements, as well as their intensity within the steel construction of the truss joint. The deduced displacements and stresses stem from the static and dynamic loadings of the excavator. It is confirmed by the actual application at the most loaded truss joint of the working wheel's loadcarrying structure of rotating excavator SRs-630 under static and dynamic loads, specific for concrete working conditions. 
- The magnitudes of the stresses and displacements obtained through research of the stress-deformed shape of the riveted and welded truss joint, give orientation data which can be used in relation to the riveted and welded truss joints of other rotating excavators under similar dynamic conditions of exploitation. That is why it is commendable because the theoretical and experimental examinations of rotating excavators of any type are hard, long lasting and expensive procedure.

- The data derived from the research conducted in this article are important because they can be further used for multiple purposes. Its primary purpose is to evaluate the actual loading and the average one upon the working wheel's loadcarrying structure of the subject excavator, as well as the most loaded truss joint in the existing design and the proposed welded design, being the optimal solution for it. But these data can be implemented for verification of the static strength of the joining elements of this truss joint and to determine the values of the safety factor and reliability coefficient. All these parameters are important indicator in the further exploitation of the excavator.

\section{References}

[1]. TAKRAF. (1986). Technical papers by manufacturer for the excavator SRs-630. Berlin, Germany.

[2]. Da Silva, L. S., \& Coelho, A. G. (2001). A ductility model for steel connections. Journal of Constructional Steel Research, 57(1), 45-70.

[3]. Steel Construction (AISC). (2005). Steel Construction Manual, 13th ed. Chicago, USA.

[4]. Haug, E. J. (1994). Computer aided kinematics of mechanical systems. Allyn and Bason. Boston, USA.

[5]. Rojlance, D. (2000). TRUSSES. Department of Materials Science and Engineering, Massachusetts Institute of Technology. Cambridge, UK.

[6]. Hubka, V. (1982). Principles of Engineering Design. Butterworth and Co (Publishers) Ltd. London, UK.

[7]. BATHE, K. J. (1982). Finite element procedures in engineering analysis (No. BOOK). Prentice-Hall.

[8]. Zienkiewicz, O. C., \& Taylor, R. L. (2005). The finite element method for solid and structural mechanics. Elsevier.

[9]. Díaz, C., Martí, P., Victoria, M., \& Querin, O. M. (2011). Review on the modelling of joint behaviour in steel frames. Journal of constructional steel research, 67(5), 741-758.

[10]. Radić, I., Markulak, D., \& Mikolin, M. (2010). Design and FEM modelling of steel truss girder joints. Strojarstvo: časopis za teoriju $i$ praksu $u$ strojarstvu, 52(2), 125-135.

[11]. Hristovska, E. (2015). Establishing a methodology for experimental measuring of loads and stress state determination on clamp dogs of carrying structures. Tribology in industry, 37(4), 464-472.

[12]. McKelvie, J. (1998). Moiré strain analysis: an introduction, review and critique, including related techniques and future potential. The Journal of Strain Analysis for Engineering Design, 33(2), 137-151.

[13]. Lazzarin, P., Quaresimin, M., \& Ferro, P. (2002). A two-term stress function approach to evaluate stress distributions in bonded joints of different geometries. The Journal of Strain Analysis for Engineering Design, 37(5), 385-398.

[14]. Sedmak, A., \& Radu, D. (2014). „Truss Beams Welded Joints-Manufacturing Imperfections and Strengthening Solutions". Journal Structural Integrity and Life, 14(1), 29-34. 